\section{TREATMENT OF CROPS BY ELECTRIC DISCHARGES.}

PROF. HENDRICK has described in the Scottish Journal of Agriculture (vol. i., I9I8, pp. 4I-5I) the results of some extensive experiments on the treatment of growing crops with an overhead electric discharge. The work was carried out during the years I913, I9I4, I9I6, and 19I7 on Mr. Low's farm of Mains of Luther, Kincardineshire. The apparatus was that of the Agricultural Electric Discharge Co., Ltd., consisting of an interrupter, induction coil, and Lodge valves. The overhead installation consisted of a number of fine wires (the diameter is not stated) arranged $\mathrm{x}_{5} \mathrm{ft}$. apart, and alternately bare and cottoncovered; these wires were about II ft. from the ground at the centre and $\mathrm{I}_{5} \mathrm{ft}$. near the supports. The experimental area consisted of ten plots, each 0.56 acre, half of each plot being electrified and half used as a control; the control areas lay south-east of the electrified ones. In I9I4 a galvanised-wire netting ( $\frac{1}{2}$-in. mesh) was placed between the electrified and control areas. A five-course rotation was followed (turnips, barley, hay, potatoes, and oats), and the ten plots were so arranged that in each season "two whole plots were under each of the crops of the rotation." In r9i7 the treated barley showed an increase in grain of $3 \mathrm{r}$ per cent. over the control, but this result was not obtained in other years, and the general conclusion is arrived at that no persistent improvement was obtained in "any of the crops grown.

These careful experiments show clearly the necessity for caution in this type of work, but, unfortunately, they do not advance our knowledge of the subject. In investigations on electro-culture there are two main aspects, the agricultural and the electrical; in these experiments, however, while the agricultural conditions have been carefully considered, the electrical conditions have been treated with comparative neglect. 'The information is given that the apparatus was capable of giving a current at 60,000 to 100,000 volts, but no measurements appear to have been taken of the actual voltage employed or of the discharge current from the wires, and no data are given as to the number of hours, or the time of day, during which the discharge was employed. The experiments were certainly a failure, but we cannot sav under what electrical conditions the failure occurred. It is thus impossible to repeat the experiments or to compare them with experiments in which more successful results have been claimed.

\section{IRON-ORE OCCURRENCES IN CANADA.}

THE Canadian Department of Mines has just issued the second (final) volume of a report upon iron-ore occurrences in Canada by Messrs. E. Lindeman and L. L. Bolton. The first volume contains an account of the principal operating mines that may be considered active producers of iron-ore, and the second volume gives brief descriptions of a very large number of occurrences, some of which have been worked in the past, but are not now contributing to the output, whilst others have not been attacked. A considerable number of more detailed memoirs, such as those on the iron-ore deposits of Nova Scotia, on the Wabana iron-ore of Newfoundland, etc., have already been published by the Department of Mines, but the present work is particularly useful, as it not only summarises these, but also describes a very large number of occurrences about which no information has hitherto been available. A very useful feature, too, is the very complete series of references to any previously published descriptions of the mines or occurrences. Another, to which attention may with advantage be directed, is the large number of magnetometric maps that accompany the present report. It is pointed out in the introduction that particular attention has been devoted to these magnetometric methods, which have hitherto been but rarely employed outside Scandinavia, where they originated, because it is desired to impress the value of this method of working upon Canadian mining engineers, since definite information can thus be obtained as to the size, shape, and distribution of deposits of magnetite, while magnetometry provides a permanent record that will serve as a guide in the further exploration or development of these deposits.

\section{BRITISH SCIENTIFIC PRODUCTS EXHI- BITION.}

THE British Science Guild has carried out successfully a very useful enterprise in the British Scientific Products Exhibition, which was opened by Lord Sydenham, president of the Guild, on August I4, at King's College; Lordon. The exhibition contains many examples of products and appliances of scientific and industrial interest which, prior to the war, were obtained chiefly from enemy countries, but which are now produced in the United Kingdom. It is an impressive reminder to all of the great advance made in the production of articles of prime importance for the home and foreign markets hitherto obtained from other countries. The exhibits cover a wide range, and include chemical products and processes, physical and electrical appliances, optical apparatus, measuring and mechanical instruments, surgical, bacteriological, and pathological appliances, including X-ray apparatus, etc. In practically all the sections the degree of progress indicated by the exhibits is surprisingly great, and even where no striking development has occurred in the way of new invention, there is noticeable a marked general improvement in apparatus constructed on the recognised lines of pre-war days.

Interest naturally centres round those exhibits associated with aircraft production. Here the developments and the differences between present-day aeroplanes and those of a few years ago are clearly marked. Modern spars, for instance, are much stronger for a given weight, engines have been developed as regards both material and construction to the extent of reducing their weight by more than one-half, whilst the size and power have grown enormously and are still making advances. The metallic materials which have been produced since the outbreak of the war, and of which aircraft constructors have been able to avail themselves, have made it possible for the greater part of an aero-engine to be made of light alloys. In non-metallic materials the investigation of timber has led to some interesting results. With regard to the many fittings which go to make un the complete aeroplane, one item of outstanding interest is the magneto. Before the war the Germans had practically a monopoly in the manufacture of this article for both car and aeroplane use, the Bosch magneto undoubtedly being the most popular throughout the world. The war has changed that, and the British manufacturers have seen to it that the home-built magnetos are worthy of their name. There are now nine British firms engaged in this work, with the result that during the past four years 300,000 magnetos have been manufactured for war service alone. What is equally important is that the home-made magneto is

NO. 2547 , VOL. IOI] 
now as good as, or even superior to, the previously imported Bosch machine. The development of dope for the fabric of aeroplanes has been the subject of many investigations, and the planes of the presentday machine are rendered taut and weather-proof by means which, thoush slightly more complicated than varnishing, are many times as cfficient. The British dopes consist of a solution of cellulose acetate made from paper or some cheaper form of cellulose, or of guncotton dissolved in suitable solvents and diluted in order to reduce the solution to a workable viscosity.

Another direction in which this country was largely dependent on Germany and Austria was in carbons for arc lamps. Fortunately, one British firm undertook the manufacture of such carbons, and through its foresight and enterprise we are now in a position to be self-supporting in this direction also.

During the war much progress has been made in the manufacture of insulation and of resistance wires, both of which were largely imported from Germany. The same is true of electro-medical apparatus. The examples of these displayed at the cxhibition show that British manufacturers are capable of supplying our needs and of producing thoroughly sound products. We may pass over the interesting display which furnishes a fine example of successful $\cdot$ British production on scientific lines of instruments of a high standard, and of the exhibits of refractory materials, in which direction progress has been very marked during the past four years. This is another industry which has been established here; and with proper care British manufacturers should be able to maintain their positions in this trade after the war.

Before the outbreak of war lens-grinding machinery was either made by the individual user or imported from abroad. Now such machinery, at least equal to any imported machines, is available in sufficient variety to cover all the ordinary types of work. At the same time entirely new methods of working glass have been developed and brought into ordinary use. Some of these methods are particularly well adapted to the manufacture of standardised optical systems. The most striking development in this respect has been the way in which enormous numbers of prism binoculars, sighting and other small telescopes, have been made to meet the demands of the military and naval authorities.

The gradual awakening of the British glass industry since the early days of the war, as revealed by the exhibition, is a feature which deserves particular mention. The two immediate needs were chemical glass and optical glass. Let it be said to the credit of British industry that in regard to optical glass a wellknown British firm near Birmingham started the manufacture of this in 1848 and kept it alive at considerable pecuniary sacrifice. Since the outbreak of war this firm's output hasincreased twenty-fold. Up to nine months after the outbreak of war there was no general and active movement among manufacturers to take up new work. Since then steps have been taken to speed up glass manufacture in general, and from the beginning of 1916 the trade has rapidly progressed from a state of dependence or doubt to one of determined optimism. The exhibition provides some measure of the material results of the reawakening of the glass industry in this country.

The Munitions Inventions Department of the Ministry of Munitions exhibits some of the results which have acrrued from the research undertaken on the nitrogen problem. This takes the form of a unit. plant for the oxidation of ammonia to oxides of nitrogen. This process was not in extended use outside Germany before the outbreak of war, but there is reason to believe that the Germans have relied on it very largely for their output of nitric acid for explosives, as well as in the manufacture of sulphuric acid by the chamber process, as a substitute for Chile nitrate, which, owing to our blockade, they have been unable to obtain. The method is now in use in this country, and several large firms, such as Brunner, Mond, and Co., Ltd., and the United Alkali Co., Ltd., are using apparatus similar to that shown. The apparatus is on view continually during the period of the exhibition. Demonstrations are given by an officer of the Munitions Inventions Department on Wednesdays at $4.30 \mathrm{p} . \mathrm{m}$.

In a preliminary review of the exhibits which, will be displayed at King's College until September 7 it is difficult to do more than give an outline of the development which has been achieved under the pressure of war conditions. For instance, much can be said about the development of the dye industry, which was so backward in this country prior to I9 14 that the outbreak of war disclosed a dependence on Germany for our supplies of dyes that was little short of appalling. The serious position in which we were placed is evident when it is realised that qur trade in cotton and woollen goods, as well as the requirements for leather staining and a multiplicity of minor industries, could be carried on only with the aid of these essential materials. How the difficulties have been overcome and the dye industry and industries associated with it placed on a firm footing will provide a most interesting chapter in the industrial history of these days. What has been achieved can be seen at King's College, and is certainly worthy of attention. Dependent upon the dye industry is that of drugs and fine chemicals, and the progress made during the war has rendered the Empire self-supporting in regard to its supplies of these essential articles.

The aim of the exhibition is to stimulate public interest and confidence in the capacity of British science combined with industrial enterprise to secure and maintain a leading place among progressive nations; and the object is the full development of our mental and material resources. It has been popularly assumed that useful scientific work was almost a prerogative of Germany, whereas a slight acquaintance with scientific history would show that most modern industries have originated with British science and invention. In purely scientific research of initiative quality we have been the pioneers; where we have been deficient is in the practical use of the results obtained and the application of our natural scientific genius to the solution of industrial problems. In order to ensure that full use is made of our capacity in this respect in the future, it will be necessary to provide for the training and employment of many more scientific technologists than have hitherto been available in this country. The adequate supply of highly trained scientific workers and technologists is, indeed, a'matter of the utmost gravity and urgency, and upon it undoubtedly depends the prosperity and safety of the country after the war, as well as the development of the natural resources of the Empire and the production of our industries on a scale greatly in excess of anything we have hitherto achieved. The Education Act has provided for elementary and continuative education by which the rank and file will be equipped for the struggles of the future, but from the point of view of industrial development it is even more important to secure a supply of highly trained captains of industry and pioneers of applied science. Modern progress in industrial and commercial fields depends upon these leaders, and the State that neglects the training of them in adequate numbers cannot expect to maintain a high place among the progressive Powers of the world. 